\title{
Investigation of Wash Fluid Preheating on the Effectiveness of Online Compressor Washing in Industrial Gas Turbines
}

Roupa Agbadede ( $\square$ roupaagbadede@yahoo.com )

Rivers State University of Science and Technology

Biweri Kainga

University of Port Harcourt

\section{Research}

Keywords: Gas Turbine, Compress Cascade, Performance Analysis, Deminralized Water, Preheating, Compressor Washing

Posted Date: July 20th, 2020

DOI: https://doi.org/10.21203/rs.3.rs-41657/v1

License: (c) (i) This work is licensed under a Creative Commons Attribution 4.0 International License. Read Full License 


\title{
Investigation of Wash Fluid Preheating on the effectiveness of online Compressor Washing in Industrial Gas Turbines
}

\author{
*Agbadede, R., ${ }^{1}$ and Kainga, B. ${ }^{2}$ \\ ${ }^{1}$ Department of Electrical Engineering, Nigeria Maritime University, Okerenkoko Warri, Delta \\ State, Nigeria. \\ ${ }^{2}$ Department of Mechanical Engineering, University of Port Harcourt, Choba, Rivers State, \\ Nigeria
}

Email: roupa.agbadede@nmu.edu.ng,roupaagbadede@yahoo.com

\begin{abstract}
This study presents an investigation of wash fluid preheating on the effectiveness of online compressor washing in industrial gas turbines. Crude oil was uniformly applied on the compressor cascade blades surfaces using a roller brush, and carborundum particles were ingested into the tunnel to create accelerated fouled blades. Demineralized water was preheated to $50^{\circ} \mathrm{C}$ using the heat coil provided in the tank. When fouled blades washed with preheated demineralized and the one without preheating were compared, it was observed that there was little or no difference in terms of total pressure loss coefficient and exit flow angle. However, when the fouled and washed cases were compared, there was a significant different in total pressure loss coefficient and exit flow angle.
\end{abstract}

Key words: Gas Turbine, Compress Cascade, Performance Analysis, Deminralized Water, Preheating, Compressor Washing 


\section{INTRODUCTION}

Gas turbines, being air breathing machines, ingest large volume of airflow which contains contaminants that foul the compressor blade surfaces, thereby degrading the overall performance of the gas turbine. Online compressor washing is a promising method of preventing/ recovering the effects of fouling on the compressor blades. However, proper strategies need to be implemented for online compressor washing to be effective since it is conducted when the engine is in operation. Three different wash frequencies of 120, 352 and 700 operating hours on the gas turbines were investigated by Stalder [1]. Wash frequency of 120 hours was reported to have generated highest performance among the three different frequencies investigated. Boyce and Gonzalez [2] pointed out the effects of prolong operation without conducting any form washing in their study. The authors reported that the engine washed twice every week shows only a slight reduction of about $0.2 \%$ in compressor efficiency as against $2.5 \%$ for the case without washing. Kolkman [3] used weight percentage of deposits removed as a measure for cleaning effectiveness when two different categories of cleaners were applied on aluminium test coupons fouled with carbon deposit. The author stated that both cleaners proved effective for cleaning the fouled blades.

Mund and Pilidis [4] in their numerical study reported better mixing of the injected fluid and the air flow for one washing system over the other. Since online compressor washing is conducted when the engine is operation, washing strategies need to be implemented to achieve effective washing. One of these strategies is preheating of the washing fluid prior to injection. Some studies have proclaimed that heating of the wash fluid is beneficial, especially in offline compressor washing where there is need for cooling down before washing to prevent thermal stresses [5].

According to Salder [1], wash fluid is preheated to enable earlier injection so as to reduce downtime associated with offline washing. For heavy duty industrial gas turbines, it is a common practice to preheat the wash fluid to about $60^{\circ}$ to $70^{\circ} \mathrm{C}$ to reduce waiting time for the engine to cool down, especially for offline compressor washing [6].Fielder [5] stated that improved washing efficiency was achieved in marine application due to wash fluid preheating. However, Engdar et al. [7] reported in their numerical study that preheating the wash fluid plays no role regarding the cleaning effectiveness. The authors attributed their claim to the fact that droplet temperatures adjust close to air flow temperature before it gets to the compressor.

From literature research, it is obvious that there is a misconception about the impact of wash fluid preheating on the washing effectiveness. This is because some researchers have proclaimed that it is beneficial to preheat the wash fluid prior to washing, while others are of the contrary view. This study presents an investigation of wash fluid preheating on the effectiveness of online compressor washing in industrial gas turbines.

\section{Methods and Materials}

The injector system employed in this study comprises a high pressure piston pump, tank and a mechanical traverse unit where the nozzle is attached (see Figures 1). The tank is capable of containing 40litres of wash fluid and it has a heat coil which can be used for heating the wash fluid before being injected (see bottom right of Figure 1). A piston pump of $5.5 \mathrm{Hp}$ as shown in bottom left of Figure 1, driven by a $2.2 \mathrm{KW}$ electric motor which runs at $1128 \mathrm{rpm}$, was used to inject the wash fluid from the tank through the nozzle tip at high pressures. A knob in the control panel is used to regulate the pressure at which the fluid is being injected. Top right of Figure 1 shows the control panel for the washing system. Also, a thermocouple shown figure 2, located externally from the tank, was used to measure the temperature of the wash fluid. Thermocouple readings are in degree Celsius.
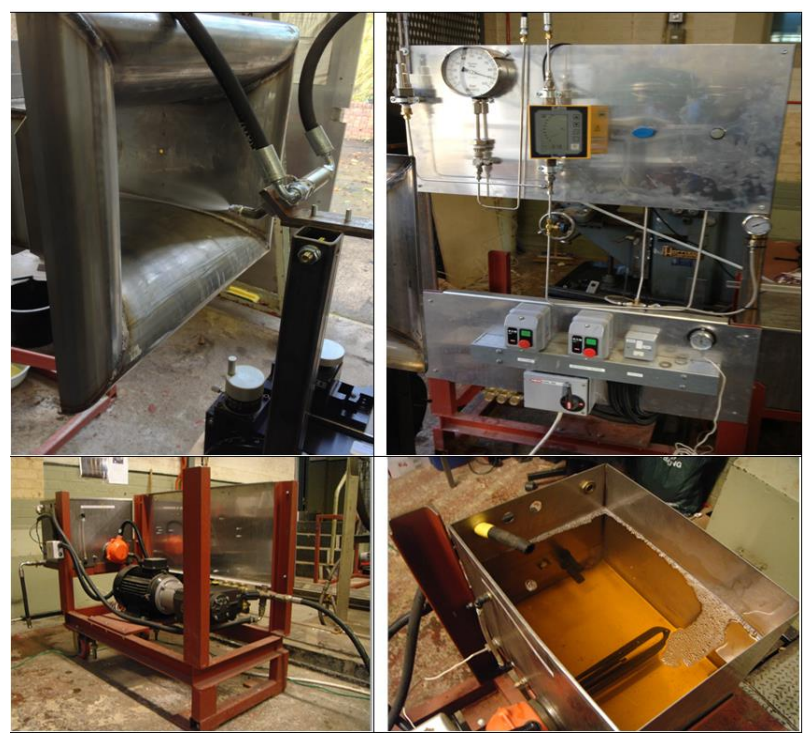

Figure1: Washing System

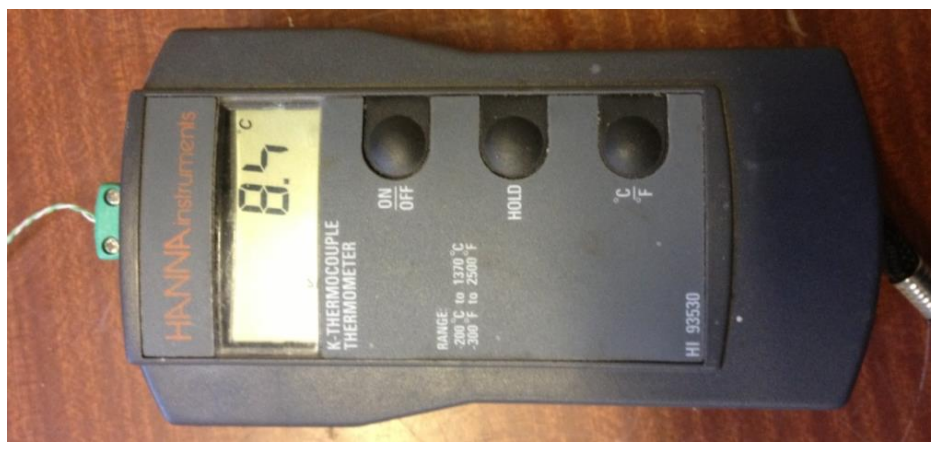

Figure2: Thermocouple 
Prior to the investigation wash fluid preheating on the effectiveness of online compressor washing in industrial gas turbines, the injection fluid droplets for the preheated and without preheated cases were sized using a laser diffraction particle analyzer shown in Figure 3. The Spraytec particle analyzer employed to measure the droplet size of the nozzle under preheated and non preheated conditions, uses laser diffraction method. The equipment utilizes angular intensity scattered light to measure the droplet when a spray passed through a laser beam. The appropriate optical model is then used to analyze the scattered light pattern recorded to yield a size distribution.

In this study, injection distance was considered based on the need to account for distance from the cascade inlet plenum to the blades. The injection distance was varied from 50 to $200 \mathrm{~mm}$, in steps of $50 \mathrm{~mm}$ to account for the effects of injection distance on the droplet sizes.

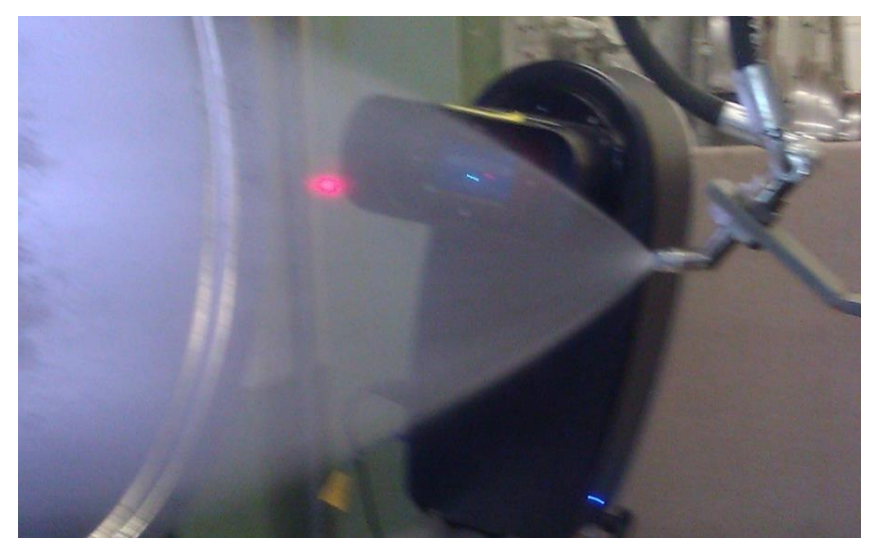

Figure 3: Spray Particle analyzer system

\section{COMPRESSOR CASCADE FOULING}

To carry out the investigation of wash fluid preheating on the effectiveness of online compressor washing, a suction wind tunnel compressor cascade shown Figure 6 was employed. The wind tunnel has nine untwisted NACA 65 series blades and when operated at full valve opening, it has a mass flow handling capacity of $5 \mathrm{~kg} / \mathrm{s}$ through an inlet area of $0.043 \mathrm{~m}^{2}$. In addition, when the control valve fully opened, the cascade operates at a Mach number of 0.3 and Reynolds number of $3.8 \times 10^{5}$.

Each of the 9 two dimensional blades in the cascade has a length, chord and a pitch-to-chord ratio of $180 \mathrm{~mm}, 60 \mathrm{~mm}$ and 0.8 respectively. In addition, to achieve high pressure rise, all the blades are positioned at zero incidence angle. A $45 \mathrm{~kW}$ electric motor which runs at $2995 \mathrm{rpm}$ is used to drive the centrifugal fan which produces the suction effect of the tunnel. Design specifications of the cascade blades are given in Table 1
Table 1: Cascade blade design Specifications

\begin{tabular}{ll}
\hline Design Parameter & Value \\
\hline Blade Inlet Angle (degrees) & 51 \\
\hline Blade Outlet Angle(degrees) & 34 \\
\hline Camber (degrees) & 30 \\
\hline Stagger Angle (degrees) & 36 \\
\hline De Haller Number & 0.7 \\
\hline Profile Shape & NACA 65 series \\
\hline S/c Ratio & 0.8 \\
\hline Inlet Mach Number & 0.3 \\
\hline Passage Width(mm) & 48 \\
\hline
\end{tabular}

The present experimental study was carried out by taking measurement of the flow at the mid-span of the three middle blades to avoid interference of boundary layer on the measured results based on the suggestion of Dixon [8]. The measurements of total and static pressures were measured using the pitot static tube at one chord upstream of the three middle blades. Measurements were taken at this point to ascertain the inlet flow conditions. While for the exit flow conditions, a three hole was employed at one chord downstream of the three middle blades to take measurement of exit flow angle, velocity, total and static pressures. One chord downstream of the blades was chosen because at this point, information about exit flow conditions can be obtained. A reference point between blades 4 and 5 was chosen and the three-hole probe was nulled at that point. The measurements were taken at every one millimeter by traversing the three-hole probe between $-40 \mathrm{~mm}$ to $120 \mathrm{~mm}$. In addition, to ensure that relatively accurate results were obtained for the measurements, the readings were taken thrice at every measurement point. Consequently, averaged values of the reading were recorded. According Gostelow and Pollard [9] taking measurements at one chord downstream of the blade is reasonable in the sense at that point the flow is fully mixed. 


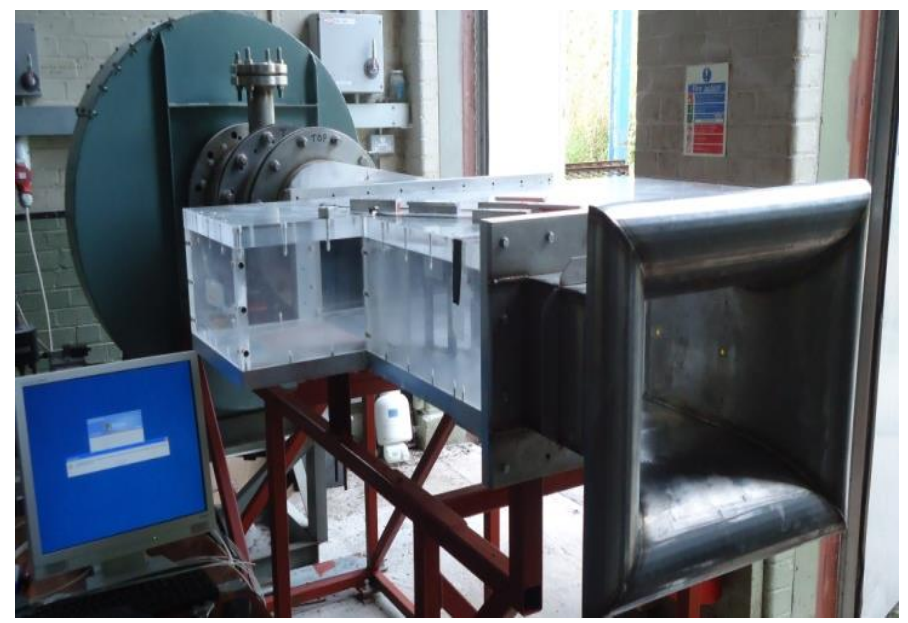

Figure 4: Suction wind tunnel compressor Cascade

This study employs the ingestion of particles into a wind tunnel compressor cascade to create an accelerated roughness (fouling) that degrades the blade profile. Details of the the fouling device employed in this study are presented in [10]. This fouling device was employed with the aim of having control of the fouling level, so as to be fairly repeatable in the accelerated fouling process.

In this study, crude oil was applied in a uniform manner on the both sides of the blades by using a roller brush in order to ensure repeatability of the process before ingesting about $1.5 \mathrm{~kg}$ of carborundum (100microns) particles on the blades to create the accelerated fouled blades(see Figure 5). The accelerated fouled case achieved in this study can be compared to a gas turbine operated in a desert environment having lube oil leakage. Figure 5 shows the three middle blades, fouled due to ingestion of particles, which can be related to a severely fouled industrial GT compressor operated in a desert for about $8000 \mathrm{hrs}$ without any filtration system or maintenance activity. MeherHomji and Bromley [11] indicates that the deposition of particles in a GT compressor is increased when oil vapour and oil leakages are present. A similar procedure was adopted herein to increase the particle deposition rate through the application of crude oil on the three middle blades

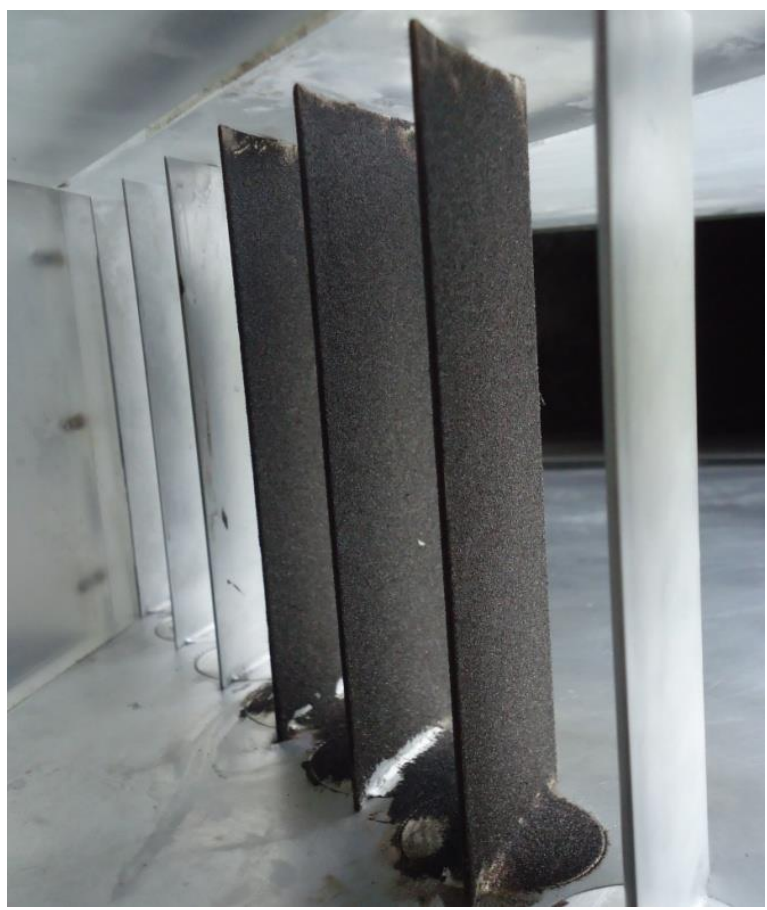

Figure 5: Fouled and Washed Blades

\section{COMPRESSOR CASCADE WASHING}

Two washed cases namely blades washed with preheated demineralised water and blades washed with demineralised water (without preheating) were considered.

In this first scenario, blades washed with preheated demineralised water, about 40litres of demineralised water was preheated to $50^{\circ} \mathrm{C}$. Heating of the wash fluid was achieved by first pouring the 40liters of demineralised water into tank, followed by switching on the heat coil in the tank as shown in top right of Figure 1. After allowing for some minutes, the demineralised water was stirred using rectangular shaped plastic, to achieve uniform temperature of the wash fluid. Consequently, the wash fluid temperature was measured using a thermocouple. After ensuring that the temperature of the wash fluid was at $50^{\circ} \mathrm{C}$, the fouled compressor cascade blades were then washed by switch on the pump where the wash fluid was injected 90 bar injection through the single nozzle positioned at mid-span of the tunnel intake (see top left Figure 1). Similarly, for the case without preheating the of the wash fluid, 40 litres of demineralised water was poured into the tank, following switch on the injector system in order to wash the fouled blades. It is worth mention that each was regime lasted for five minutes and the washing for the two different cases was carried out under the same operating conditions such as injection period, pressure, quantity of water etc. 


\section{Correlation of Cascade data to a theoretical compressor stage performance}

To obtain the mean theoretical mean stage performance of the compressor from the cascade experimental data, the equations derived by Howell's [14], to account for losses were used in this study.

$C_{D p}, C_{D a}, C_{D s}$ represent Profile, Annulus and Secondary drag coefficients in equation 1,2 and 3 respectively.

$$
\begin{aligned}
& C_{D P}=\frac{s}{c}\left(\frac{\Delta P}{1 / 2 \rho V_{1}^{2}}\right) \frac{\cos ^{3} \alpha_{m}}{\operatorname{CoS}^{2} \alpha_{1}} \\
& C_{D a}=0.02 \frac{s}{h} \\
& C_{D s}=0.018 C_{L}^{2}
\end{aligned}
$$

(Error! No text of specified style in document.)

Lift coefficient (CL) is given by equation 4 and 5

$$
\begin{aligned}
& C_{L}=2 \frac{s}{c} \cos \alpha_{m}\left(\tan \alpha_{1}-\tan \alpha_{2}\right)-C_{D} \tan \alpha_{m} \\
& \tan \alpha_{m}=0.5\left(\tan \alpha_{1}+\tan \alpha_{2}\right)
\end{aligned}
$$

Equation (6) below is the summation of the equations (1), (2) and (3) which gives the stage overall drag coefficient.

$C_{D}=C_{D p}+C_{D a}+C_{D s}$

In this study, correction factors derived by Howells [15] were employed to correlate the cascade data to an actual theoretical stage performance. . Also, an assumption of $50 \%$ reaction was made, this implies that the pressure rise is equally distributed between the stator and rotor where $\alpha 1=\alpha 3$ and $\alpha 0=\alpha 2$

The temperature rise coefficient is given by, Equation 7.

$$
\frac{C_{p} \Delta T_{s}}{0.5 U^{2}}=2 \lambda\left(\frac{V_{a}}{U}\right) \operatorname{an} \alpha_{1}-\tan \alpha_{2}^{-}
$$

$$
\eta_{P}=1-\left(\frac{2}{\sin \left(2 \alpha_{m}\right)} X \frac{C_{D}}{C_{L}}\right)
$$

While Pressure rise coefficient is given by, Equation 9

$$
\frac{\Delta P_{s}}{0.5 \rho U^{2}}=\eta_{P}\left(\frac{c_{p} \Delta T_{s}}{0.5 U^{2}}\right)
$$

All the blades in the cascade were assumed to have same aerodynamics in order to calculate the isentropic efficiency for the different cases. Hence, design pressure ratio of the adopted engine was used to calculate the isentropic efficiency for the different cases investigated. The isentropic efficiencies and flow coefficients were calculated using Equations 10 and 11 respectively.

$\eta_{c}=\frac{P R^{\left(\frac{\gamma-1}{\gamma}\right)}-1}{P R^{\left(\frac{\gamma-1}{m_{p}}\right)}-1}$

$\phi=\mathrm{Va} / \mathrm{U}=1 /(\tan \alpha 1+\tan \alpha 2)$

The output parameters of polytropic efficiency, flow capacity and calculated isentropic efficiency obtained from the correlations of the cascade data were implanted into gas turbine performance simulation software to simulate the overall performance of the engine for the different conditions investigated. To simulate the different conditions, a twin shaft engine specification data obtained from open domain, were used to model the engine configuration in the GASTURB simulation software.

Figure 6 shows the industrial gas turbine engine configuration model adopted for the investigations, while Table 2 presents the design point performance specifications. Modelled design point simulation interface is presented in Figure 7.

Polytropic or stage efficiency is given by, Equation 8 


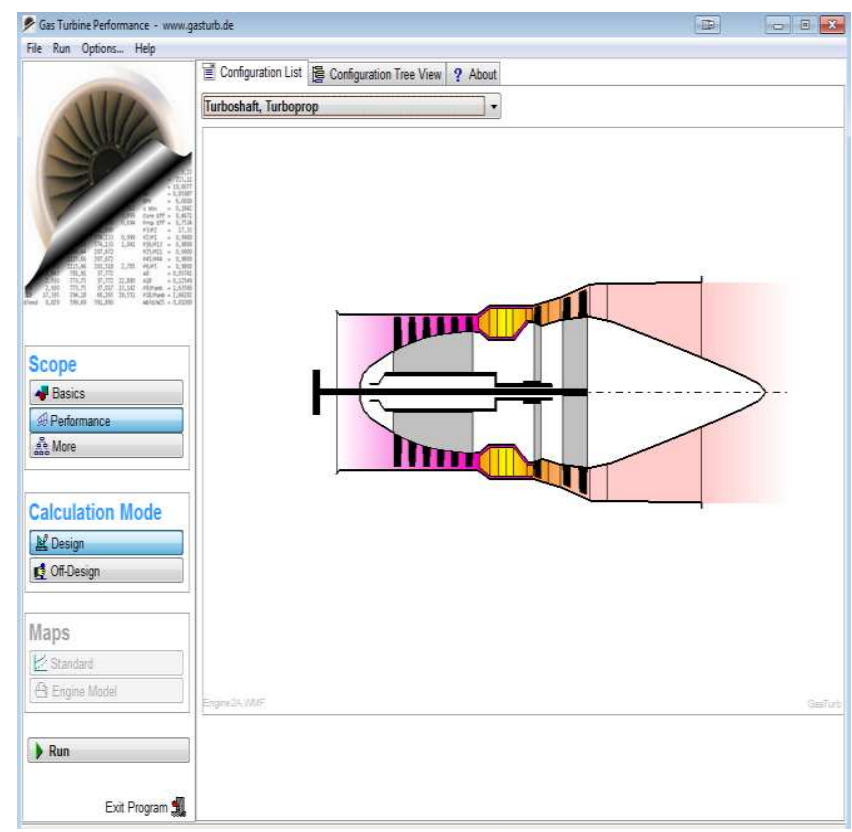

Figure 6: Industrial gas turbine engine configuration

Table 2: Engine design specifications (Courtesy of General Electric)

\begin{tabular}{cc}
\hline Design parameters & Units \\
\hline Power output & $25 \mathrm{MW}$ \\
Thermal efficiency & 36 \\
PR & 18 \\
Exhaust temperature & $839 \mathrm{~K}$ \\
Exhaust flow & $70.5 \mathrm{~kg} / \mathrm{s}$ \\
Heat rate & $9705 \mathrm{~kJ} / \mathrm{kWh}$ \\
\hline
\end{tabular}

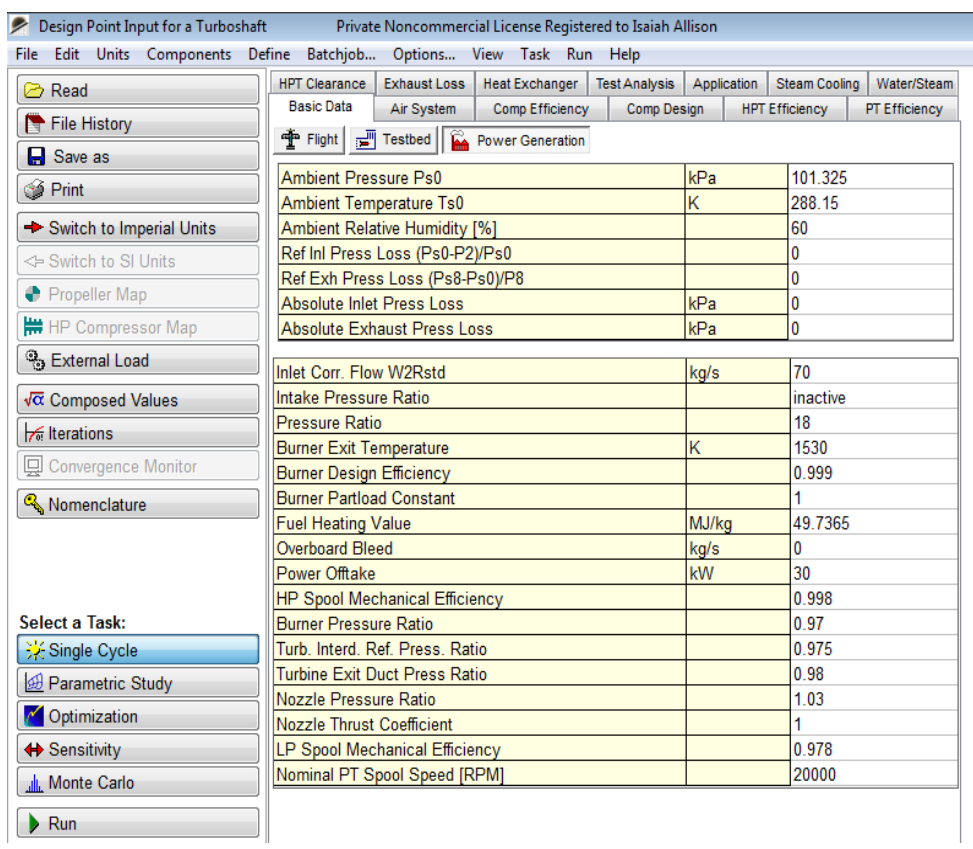

Figure 7: Modeled design point

\section{RESULTS AND DISCUSSION}

Figure 8 shows the cumulative distribution curves for preheating the wash fluid and that without preheating. As can be seen, the curves are similar. However, at larger droplet size regions, there is interlapping of the curves between the case of preheating and that without heating. This effect can be attributed to the fluid temperature being warmer than the surrounding air, thereby resulting in transfer of heat between the wash fluid and ambient air. At 90bar injection pressure, when the wash fluid heated was from 15 to $50^{\circ} \mathrm{C}$, the droplet sizes reduced from 81 to $78 \mu \mathrm{m}$. This reduction in droplet size can be attributed to the reduced viscosity of the wash fluid due to the heating, thereby resulting in finer droplet sizes. Though, the reduction in droplet size with heating of wash fluid is relatively small because of the low viscosity of water; for high viscosity fluid, heating can result in significant reduction in droplet sizes. 


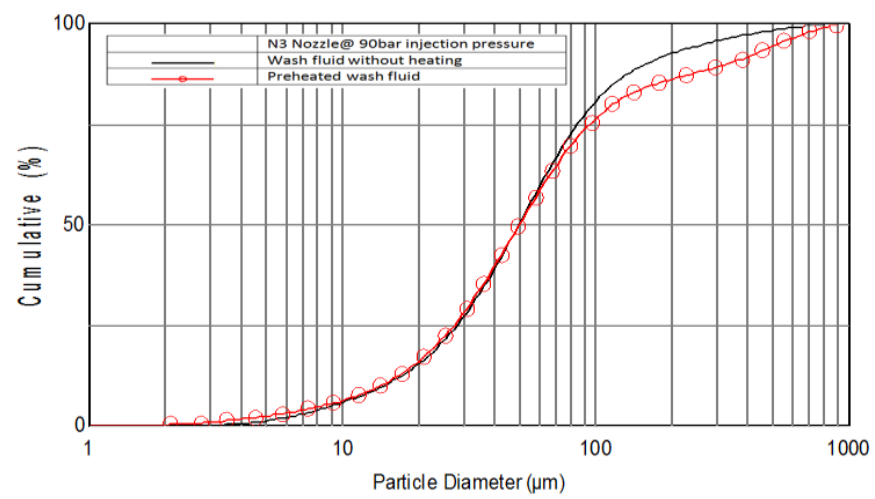

Figure 8: Cumulative distribution curves preheating the wash fluid and that without preheating at a given injection pressure

Figure 9 shows the cumulative distribution curves for varying injection distances. As can be seen, droplet size distributions are following a trend of decreasing size with increasing distance. Cumulative percentage of droplet sizes at an injection distance of $50 \mathrm{~mm}$ was larger than the $200 \mathrm{~mm}$. This can be attributed to the breakup of droplets as they exit tip of the nozzle. At the initial disintegration process, the droplets are large and unstable. As a result, the droplets undergo further disintegration known as secondary atomization into smaller droplets. Hence, close to the nozzle tip, the droplets are coarser than further downstream where the droplets become finer as a result of the breakup process.

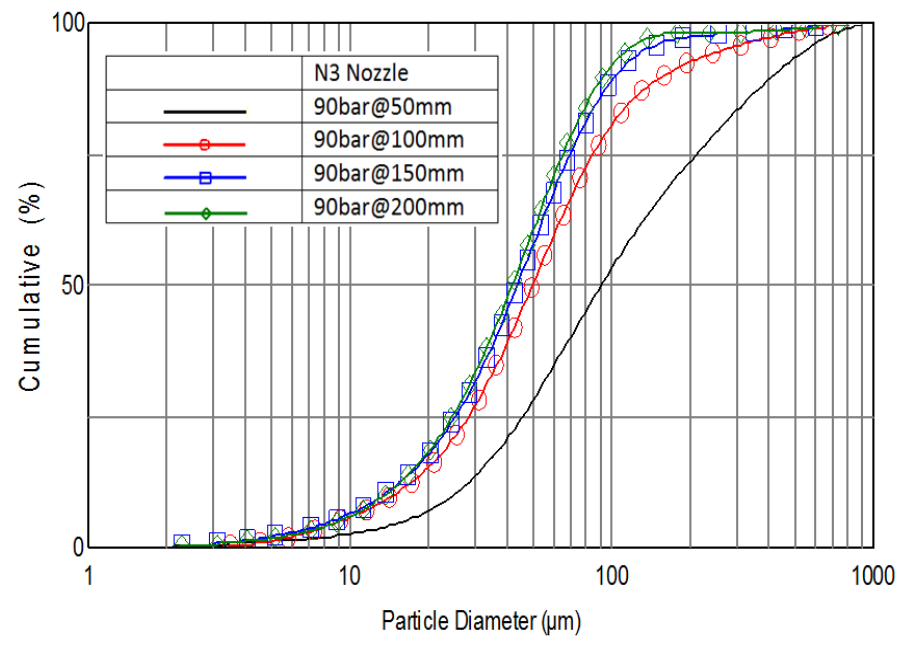

Figure 9: Cumulative distribution curves for varying injection distance

Figure 10 shows the blade aerodynamic performance plot of total pressure loss coefficient for different conditions. When fouled blades were washed with both preheated and non preheated demineralised water, the plots show a decrease in total pressure loss coefficient for the fouled case. The mean total pressure loss coefficient decreased from a fouled case of 0.109 to 0.079 and 0.082 for preheated wash fluid and nonpreheated respectively. However, when the preheated and nonpreheated cases were compared, there is slight difference in total pressure loss coefficient for different cases. The total pressure loss coefficient for blades washed preheated demineralised water is 0.079 as against non preheated wash fluid of 0.82 .

When exit airflow angle of the two cases were compared in Figure 9, the plots show that blade washed with non preheated demineralised water produced lower mean exit flow angle of 34.15 degrees as against 34.45 for preheated wash fluid (see Table 3). These mean values of aerodynamic parameters obtained in this study are similar with findings of Fouflias et al.[12] and Igie et al.[13]. Although, slight differences were observed, could be attributed to the level degradation applied in the different study or discrepancies arising from the measuring instrument. For instance, Fouflias [12] applied different levels of roughness, ranging from clean condition $(0 \mu \mathrm{m})$ to particle sizes of $354 \mu \mathrm{m}$ on the blades. For clean condition of $0 \mu \mathrm{m}$ and blades roughness of $354 \mu \mathrm{m}$, the author reported total pressure loss coefficient both cases 0.16 and 0.35 respectively. While the exit flow angle were 34 and 39.5 degrees respectively. Similarly, Igie et al.[13] reported total pressure loss coefficient of $0.056,0.136$ and 0.097 for clean, fouled and washed cases respectively.

Table 3: Mean Values of blade aerodynamic parameters

\begin{tabular}{lcc}
\hline Conditions & a.total (deg) & $\Omega$ \\
\hline Clean & 33.35 & 0.050 \\
Fouled & 35.44 & 0.109 \\
$\begin{array}{l}\text { Washed with Preheated demineralised Water } \\
\text { Washed with demineralised water without }\end{array}$ & 34.45 & 0.079 \\
\begin{tabular}{l} 
preheating \\
\hline
\end{tabular} & 0.082 \\
\hline
\end{tabular}

From the outcome the two blade aerodynamic performance parameters, the total loss coefficient plot shows that preheated washed produced a better recovery in aerodynamic performance; while in the case of the exit flow angle the results favoured the fouled blades with washed with non preheated wash fluid. Though, from the values, there seems to be slight difference in total pressure loss coefficient when both cases were compared. The difference seems so insignificant for aerodynamic performance parameters for both cases. Therefore, 
a valid conclusion cannot be drawn in relation to which case (fouled blades washed with preheated demineralised water or the one without preheating) produced lower/ higher total pressure loss coefficient and exit flow angle. In addition, when the preheated and non preheated conditions were compared visually, using the blade aerodynamic performance, there was little or no difference. Despite the fact that slight discrepancies were observed, regarding the trend of total pressure loss coefficient and exit flow for the two cases, the results seem to be valid. This is because significant differences in total pressure loss coefficient and exit flow angle were observed between the fouled and washed cases. Also, the slight discrepancies observed can be attributed to the resolution of the instrument used in obtaining the compressor cascade performance data in this study.

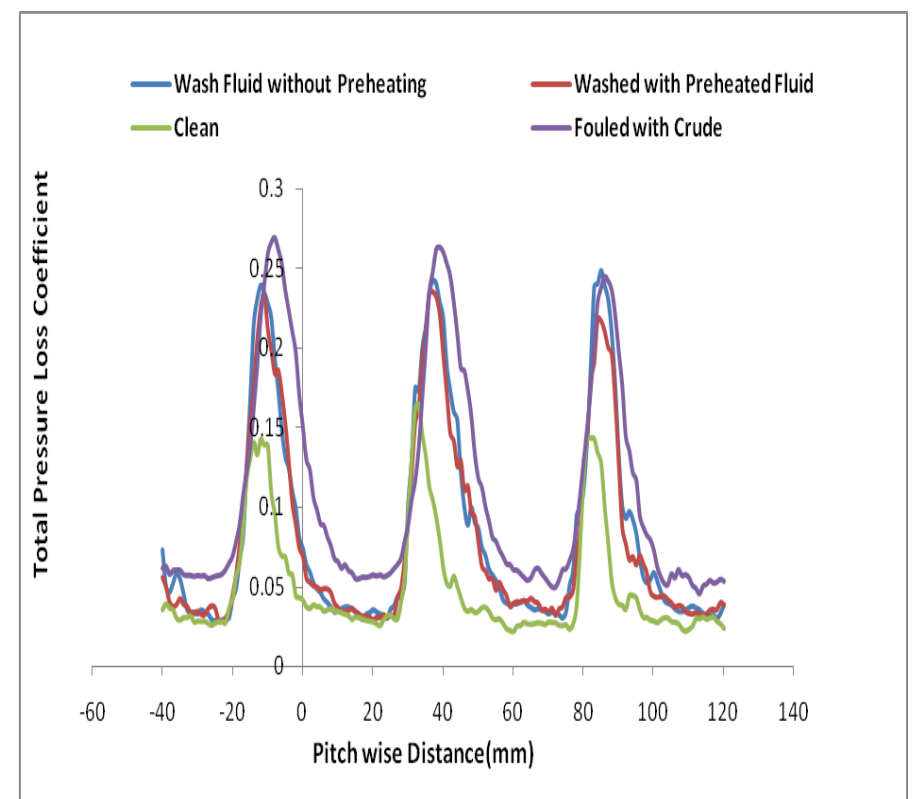

Figure 10: Total pressure loss coefficient against Pitch distance

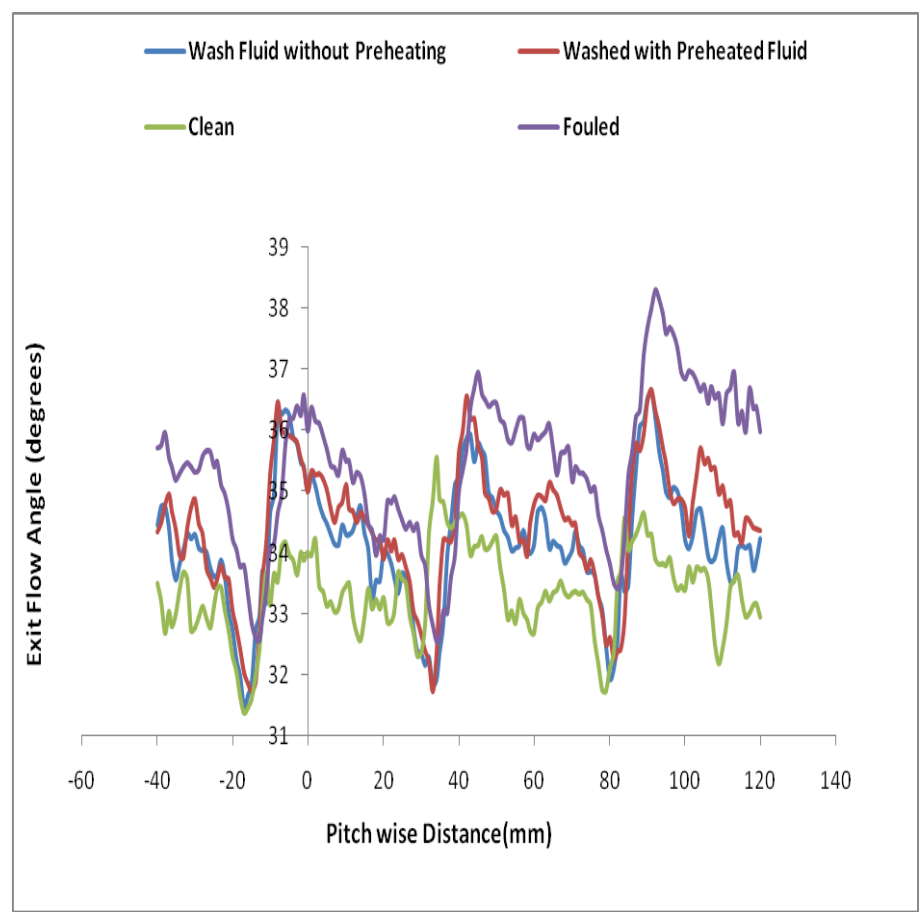

Figure 11: Exit flow angle against Pitch distance e

Table 4 presents the values of flow coefficient, polytropic and isentropic efficiencies obtained, using the Howell's method to correlate the cascade readings to an actual stage performance data. Table 5 shows the variation/reduction in isentropic efficiency and non-dimensional flow values implanted into the software, to simulate the performance of the different cases.

Table 5: Polytrophic and isentropic efficiencies and nondimensional mass flow of clean, fouled and washed cases

\begin{tabular}{llllll}
\hline Conditions & $\begin{array}{l}\text { Polytropic } \\
\text { Efficiency }\end{array}$ & $\begin{array}{l}\text { \%Variation } \\
\text { Polytropic } \\
\text { Efficiency }\end{array}$ & $\begin{array}{l}\text { Isentropic } \\
\text { Efficiency }\end{array}$ & $\begin{array}{l}\text { \% Variation } \\
\text { Isentropic } \\
\text { Efficiency }\end{array}$ & $\begin{array}{l}\text { \% variation } \\
\text { Non- } \\
\text { dimensional } \\
\text { Mass flow } \\
\text { Rate }\end{array}$ \\
\hline Clean & 91.9 & 0.0 & 88.1 & 0.0 & 0.0 \\
Fouled & 86.7 & 5.6 & 80.6 & 8.5 & 2.7 \\
$\begin{array}{l}\text { Washed with } \\
\text { Preheated }\end{array}$ & 89.7 & 2.4 & 84.9 & 3.6 & 1.3 \\
$\begin{array}{l}\text { Demin. water } \\
\text { Washed with }\end{array}$ & 89.6 & & & & \\
$\begin{array}{l}\text { Demin water } \\
\text { without }\end{array}$ & & 2.5 & 84.8 & 3.7 & 1.3 \\
\begin{tabular}{l} 
Preheating \\
\hline
\end{tabular} & & & & & \\
\hline
\end{tabular}


Table 4: Variation/reduction in Isentropic Efficiency and Non-dimensional mass flow rate

\begin{tabular}{lll}
\hline Conditions & $\begin{array}{l}\text { \% Variation } \\
\text { Isentropic } \\
\text { Efficiency }\end{array}$ & $\begin{array}{l}\text { \% variation Non-dimensional } \\
\text { Mass flow Rate }\end{array}$ \\
& 0.0 & 0.0 \\
\hline Clean & 8.5 & 2.7 \\
Fouled & 3.6 & 1.3 \\
$\begin{array}{l}\text { Washed with Preheated Demin. } \\
\text { water }\end{array}$ & \\
Washed with Demin water & 3.7 & 1.3 \\
without Preheating &
\end{tabular}

Figure 12 shows the engine performance of plot of thermal against the different conditions. As can been seen from the figure, when fouled blades washed with preheated and without demineralised water cases were compared, there was little or no difference in thermal efficiency for both cases. The percentage change between the two cases is 0.1 . However, when the fouled and blades washed with preheated demineralised water were compared, the results show an improvement in thermal by $5.37 \%$. The plot of fuel flow in Figure 13 follows a similar pattern to thermal efficiency when fouled blades washed with the preheated and non preheated demineralised water cases were compared. Also, when the fouled and washed with preheated demineralised water were compared for the fuel flow plots, a percentage change of 5.38 was recorded. These results agree with the findings in Engdar et al.[7],where the authors stated that preheating the wash fluid has no effect of the cleaning effectiveness. Also, these results validate the blade aerodynamic performance results presented earlier.

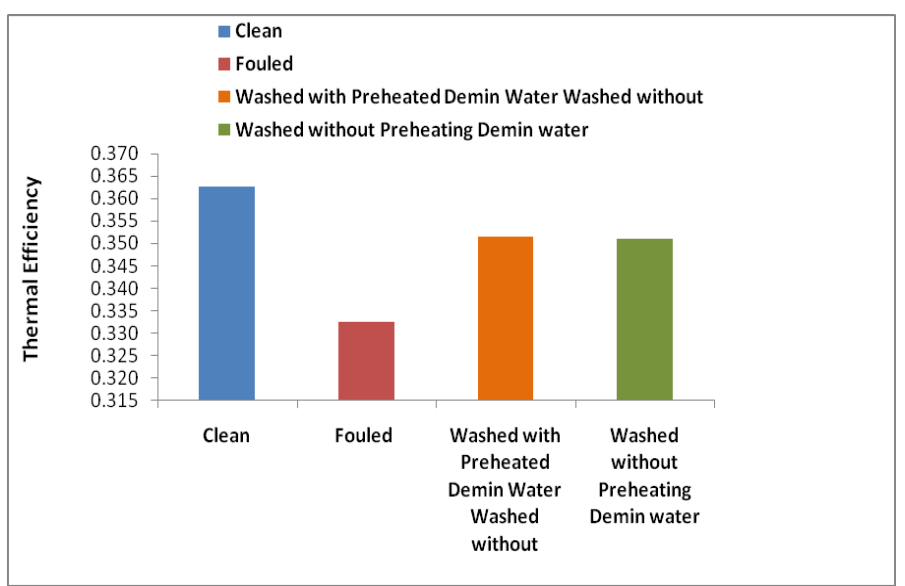

Figure 12: Plot of Thermal Efficient at Different Conditions

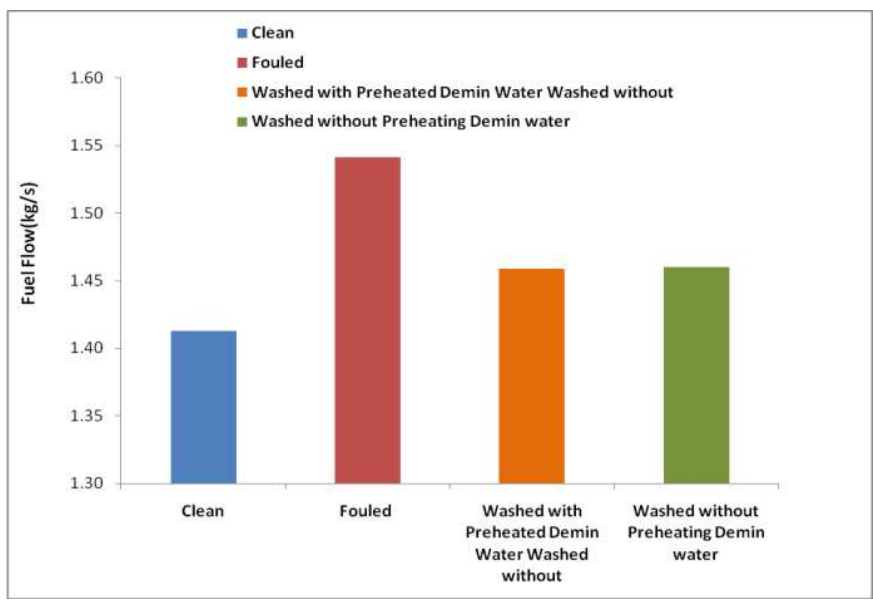

Figure 13: Plot of Fuel Flow at Different Conditions

\section{CONCLUSIONS}

An investigation of wash fluid preheating on the effectiveness of online compressor washing in industrial gas turbines is presented in this study

Compressor cascade blades of a suction wind tunnel were fouled by applying crude oil uniformly on the blade surfaces and ingesting carborundun particles into the tunnel. Washing of the fouled blades were conducted using single flat fan nozzle, where preheated and non preheated demineralised water were used separately to wash the fouled blades. The outcome of the findings from the study is presented below:

1. Fouled blades washing with both preheated and non preheated demineralised water produced a better blade aerodynamic performance than the fouled condition

2. Little or no difference was observed visually, when fouled blades washed with preheated demineralised water and non preheated cases were compared in terms total pressure loss coefficient and exit airflow angle.

3. Droplets for the preheated demineralised water generate lower Saunter mean droplet diameter as against the case without heating. 


\section{DECLARATION:}

\section{Availability of data and materials:}

All data and materials used are attached as supplementary documents

\section{Competing Interest- not applicable}

\section{Funding- not applicable}

\section{Authors' contributions:}

Roupa Agbadede - Conducted the experiments and write up of the manuscripts

Biweri Kainga - initiated concept and revision of the manuscript

\section{ACKNOWLEDGMENTS}

The authors are exceedingly grateful to Cranfield University, Department of Power and Propulsion for unfettered access to the Test House and instruments used for the experiments and R$\mathrm{MC}$ power recovery for their technical support.

\section{REFERENCES}

[1] Stalder, J. Gas turbine compressor washing state of the art: Field experiences, Journal of Engineering for Gas Turbines and Power 2001; vol. 123, no. 2, pp. 363-370.

[2] Boyce, M. P. and Gonzalez, F. A study of on-line and offline turbine washing to optimize the operation of a gas turbine, Journal of Engineering for Gas Turbines and Power 2007; vol. 129, no. 1, pp. 114-122

[3] Kolkman, H. J. (1993), "Performance of gas turbine compressor cleaners", Journal of Engineering for Gas Turbines and Power, vol. 115, no. 3, pp. 674-677.

[4] Mund, F. C. and Pilidis, P. (2005), "Online compressor washing: A numerical survey of influencing parameters", Proceedings of the Institution of Mechanical Engineers, Part A: Journal of Power and Energy, vol. 219, no. 1, pp. 13-23.

[5] Fielder, J. (2003), "Evaluation of zero compressor wash routine in RN service", 2003 ASME Turbo Expo, Vol. 3, 16 June 2003 through 19 June 2003, Atlanta, GA, pp. 543.

[6] Mund, F. C. and Pilidis, P. (2006), "Gas turbine compressor washing: Historical developments, trends and main design parameters for online systems", Journal of Engineering for Gas Turbines and Power, vol. 128, no. 2, pp. 344-353.
[7] Engdar, U., Orbay, R., Genrup, M., and Klingmann, J.,(2004) "Investigation of the Two-Phase Flow field of the GTX100 Compressor inlet During Off-line Washing," ASME GT 2004-53141.

[8] Dixon, S. L. Fluid mechanics and thermodynamics of turbomachinery 1998; 5th ed, Butterworth-Heinemann, U.S.A

[9] Gostelow, J. and POLLARD, D. Some experiments at low speed on compressor cascades(Low speed cascade tunnel experiments for improvement of airflow and testing techniques, noting porous sidewall suction effect on axial velocity changes), ASME, TRANSACTIONS, SERIES AJOURNAL OF ENGINEERING FOR POWER 1967; vol. 89, pp. 427-436.

[10] Agbadede, R., Pilidis, P., Igie, U. L., and Allison, and I. Experimental and Theoretical Investigation of Liquid Injection Droplet Size Influence on Online Compressor Cleaning Effectiveness for Industrial Gas Turbines, Elsevier the Journal of Energy Institute 2014; Vol. 88, no.4 pp. 414-424

[11] Meher-Homji, C. B. and Bromley, A. (2004), "Gas Turbine Axial Compressor Fouling and Washing", 33rd Turbomachinery Symposium, Houston,TX, pp. 163.

[12]Fouflias, D. (2009), An experimental and computational analysis of compressor cascades with varying surface roughness (unpublished $\mathrm{PhD}$ thesis), Cranfield university, Cranfield.

[13] Igie, U., Pilidis, P., Fouflias, D. and Ramsden, K. On-line compressor cascade washing for gas turbine performance investigation, Proceeding of ASME Turbo Expo, 6-10 June 2011

[14] Howell, A. (1945b), "Fluid dynamics of axial compressors", ARCHIVE: Proceedings of the Institution of Mechanical Engineers 1847-1982 (vols 1-196), vol. 153, no. 1945 , pp. $441-452$

[15] Howell, A. (1945a), "Design of axial compressors", ARCHIVE: Proceedings of the Institution of Mechanical Engineers 1847-1982 (vols 1-196), vol. 153, no. 1945, pp. 452-462.

[16] 
Figures

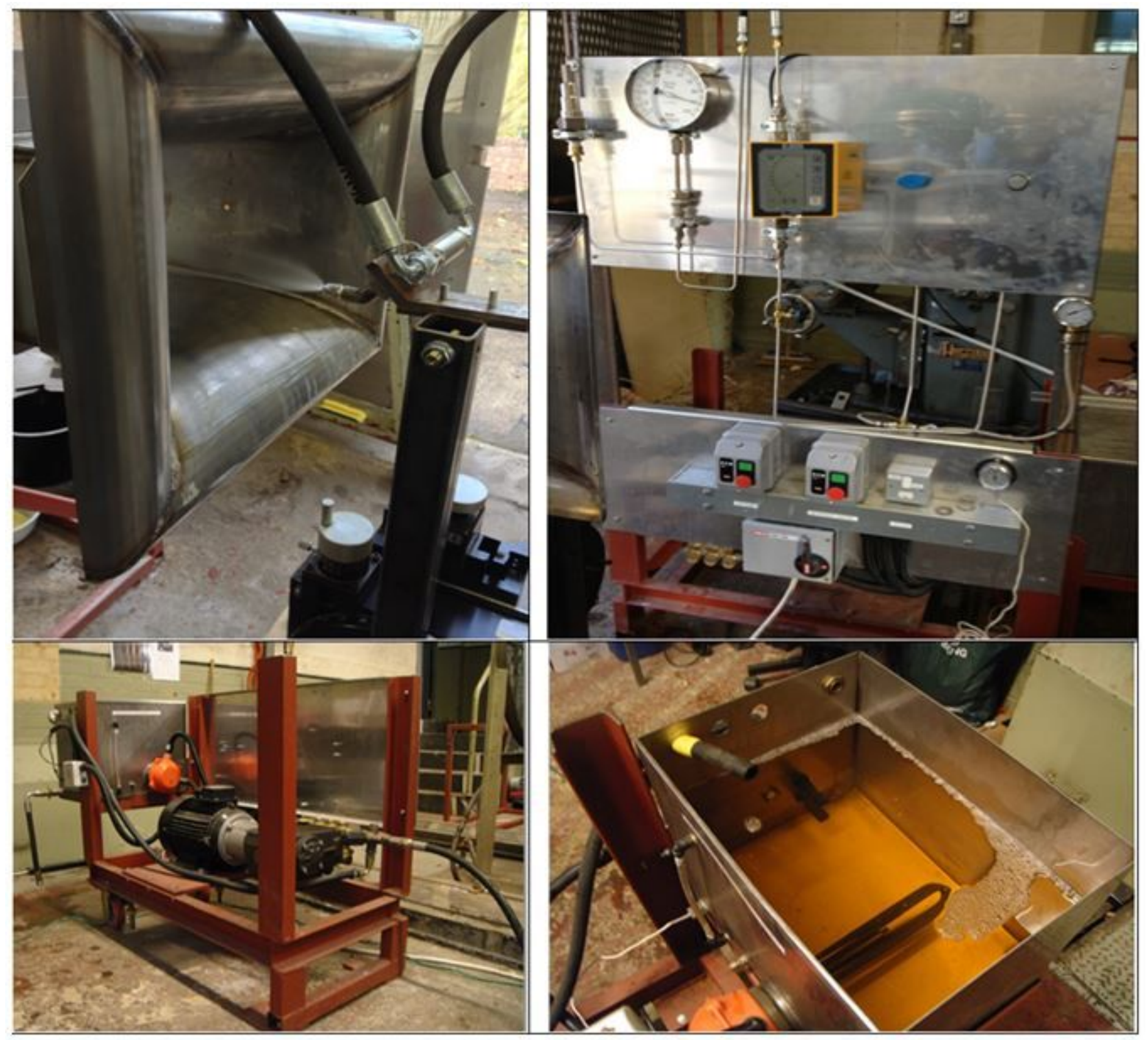

Figure 1

Washing System. 


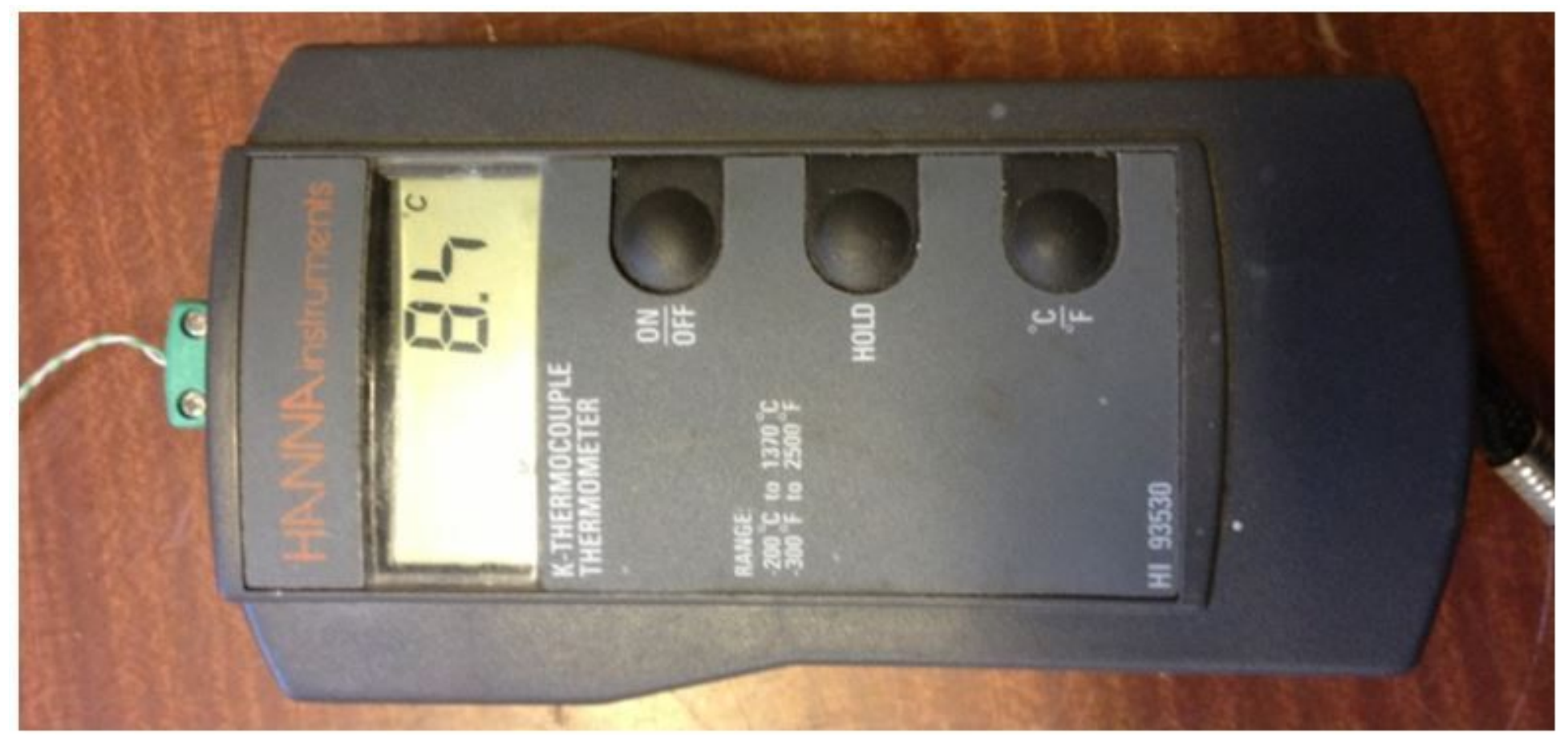

Figure 2

Thermocouple.

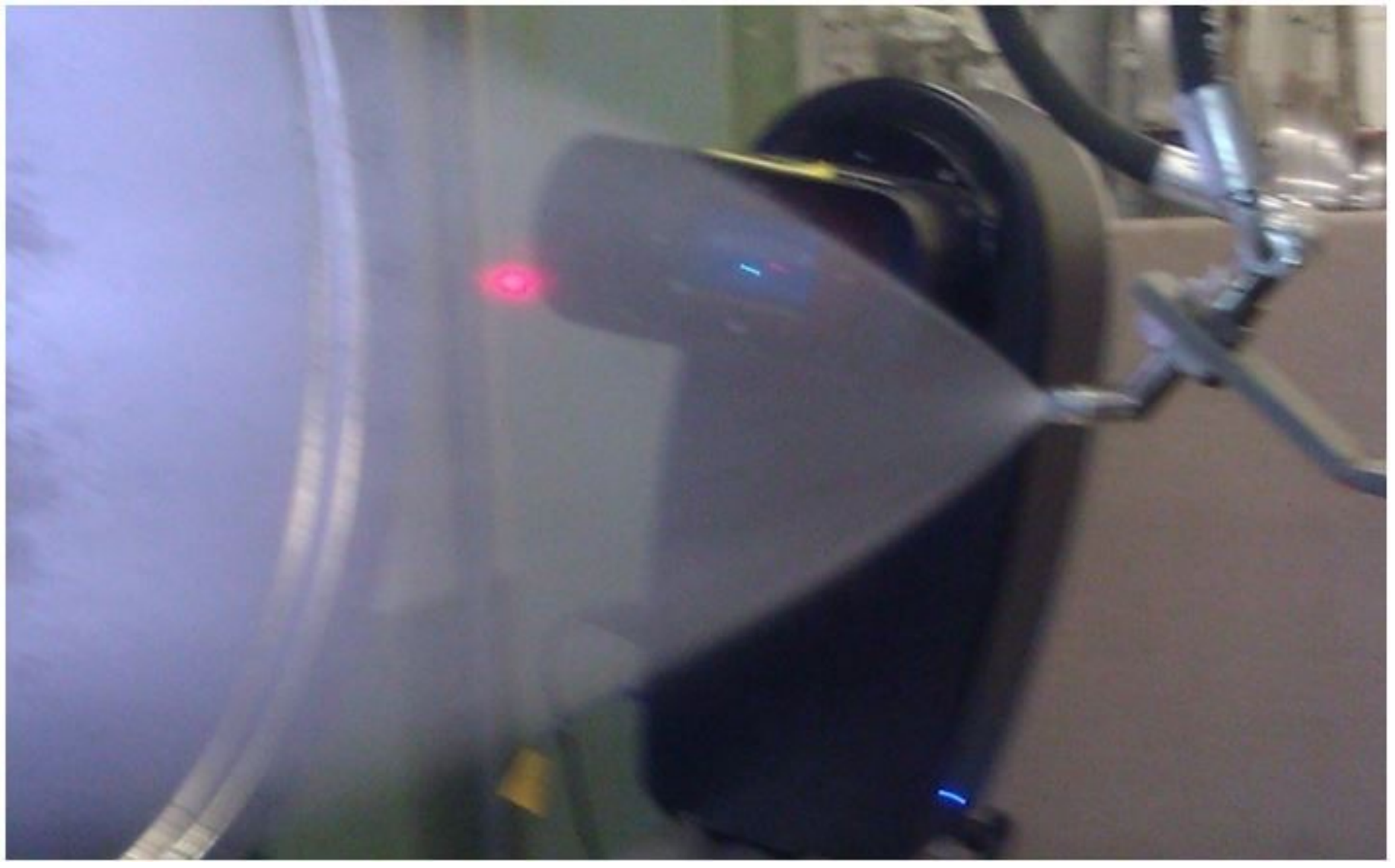

Figure 3 
Spray Particle analyzer system.

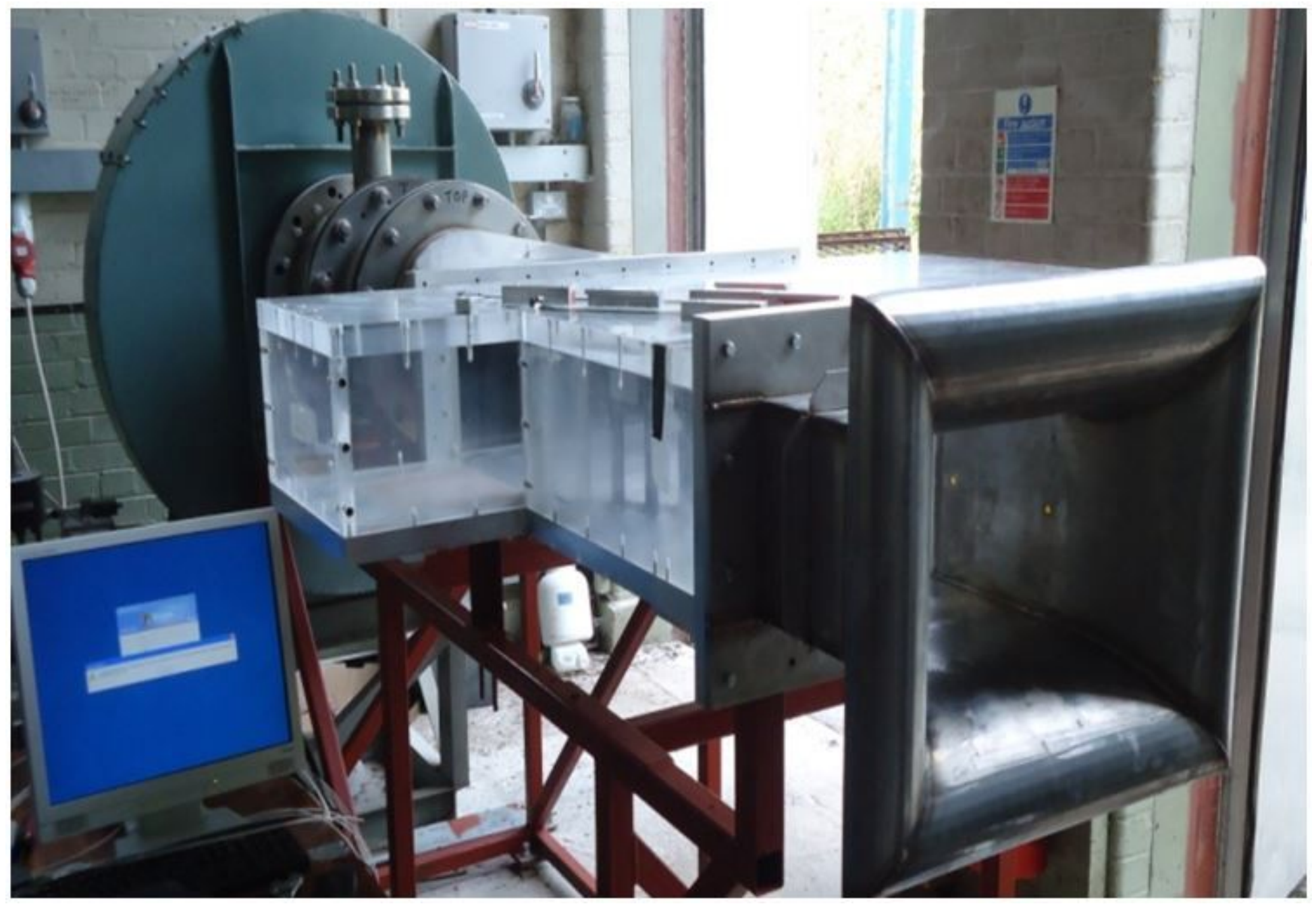

\section{Figure 4}

Suction wind tunnel compressor Cascade. 


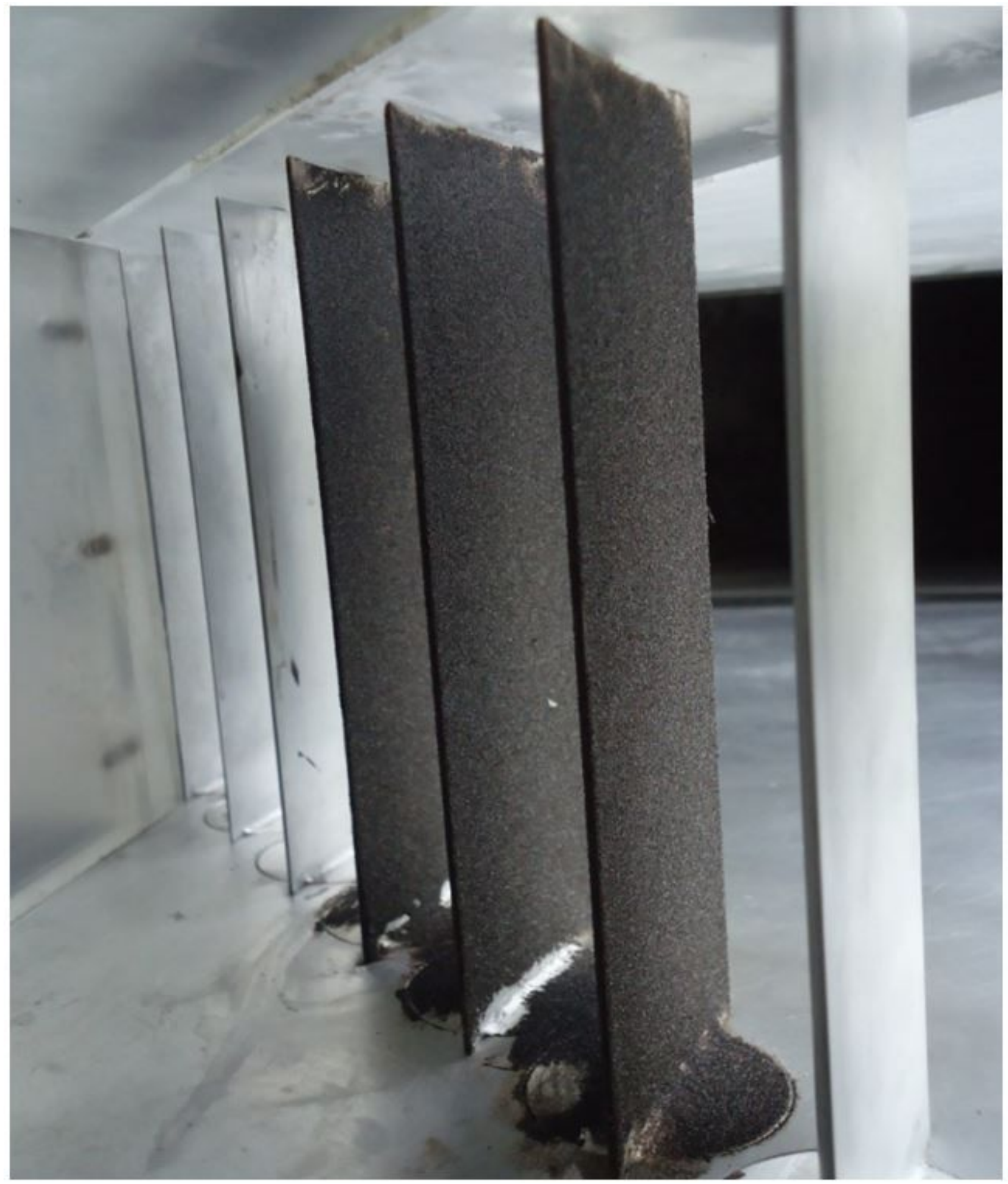

Figure 5

Fouled and Washed Blades. 


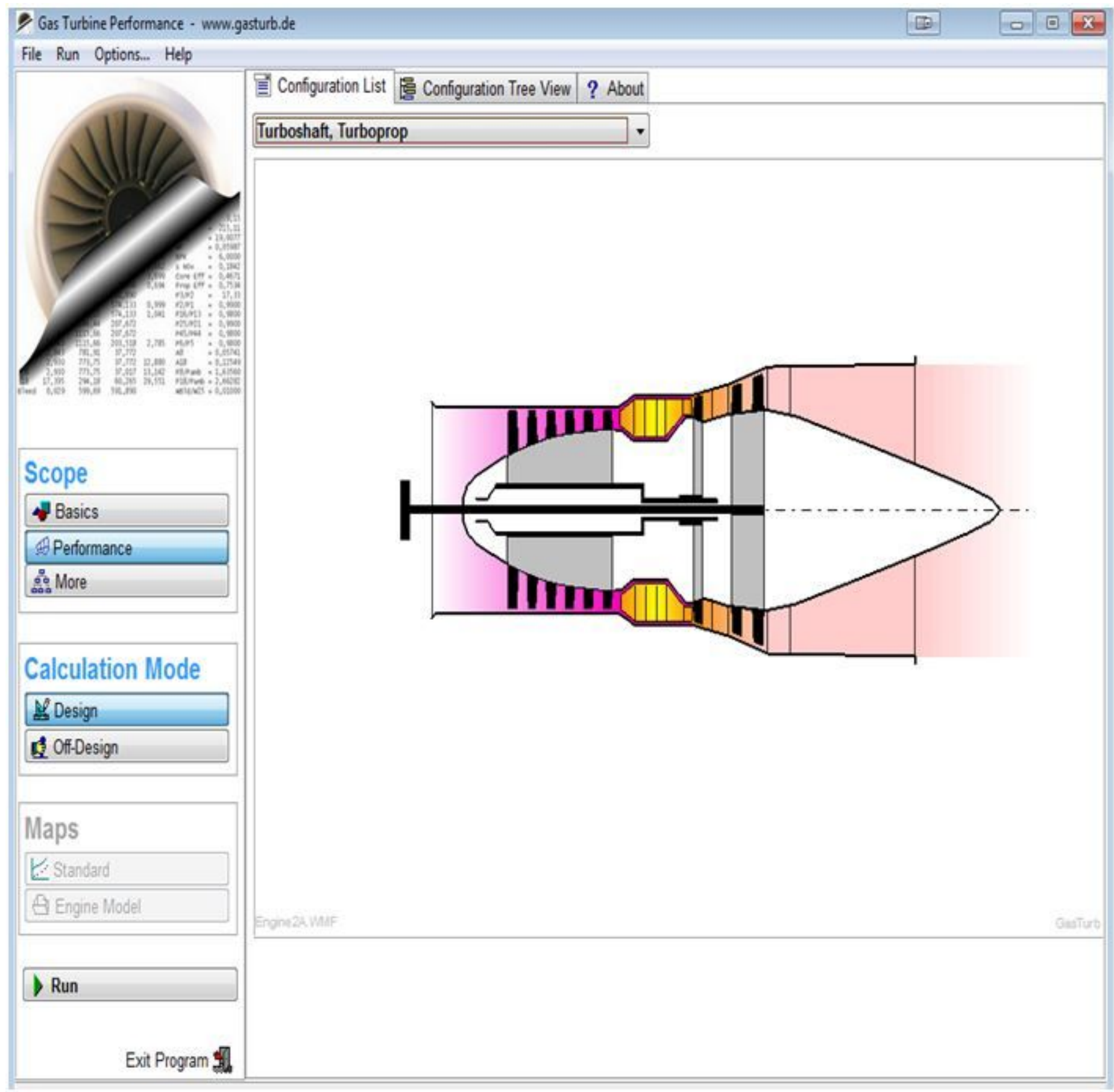

Figure 6

Industrial gas turbine engine configuration. 


\begin{tabular}{l} 
File Edit Units Components Defin \\
$\square$ Read \\
G Save as History \\
\hline Print
\end{tabular}

\section{Print}

$\Rightarrow$ Switch to Imperial Units

Switch to SI Units

- Propeller Map

쓰 HP Compressor Map

S) External Load

$\sqrt{\alpha}$ Composed Values

hor Iterations

믄 Convergence Monitor

Q. Nomenclature

\section{Select a Task: \\ Single Cycle \\ Parametric Study \\ Optimization \\ $\leftrightarrow$ Sensitivity \\ Monte Carlo}

\begin{tabular}{|l|l|l|l|l|l|l|}
\hline HPT Clearance & Exhaust Loss & Heat Exchanger & Test Analysis & Application & Steam Cooling & Water/Stean \\
\hline
\end{tabular}

\begin{tabular}{|l|l|l|l|l|l|}
\hline Basic Data & Air System & Comp Efficiency & Comp Design & HPT Efficiency & PT Efficiency \\
\hline
\end{tabular}

Fuel:

\& Flight Di Testbed

\begin{tabular}{|l|l|l|}
\hline Ambient Pressure Ps0 & $\mathrm{kPa}$ & 101.325 \\
\hline Ambient Temperature Ts0 & $\mathrm{K}$ & 288.15 \\
\hline Ambient Relative Humidity [\%] & & 60 \\
\hline Ref InI Press Loss (Ps0-P2)/Ps0 & & 0 \\
\hline Ref Exh Press Loss (Ps8-Ps0)/P8 & & 0 \\
\hline Absolute Inlet Press Loss & $\mathrm{kPa}$ & 0 \\
\hline Absolute Exhaust Press Loss & $\mathrm{kPa}$ & 0 \\
\hline
\end{tabular}

Natural Gas

Run

\begin{tabular}{|l|l|l}
\hline Inlet Corr. Flow W2Rstd & $\mathrm{kg} / \mathrm{s}$ & 70
\end{tabular}

\begin{tabular}{|l|l|l|}
\hline Inlet Corr. Flow W2Rstd & $\mathrm{kg} / \mathrm{s}$ & 70 \\
\hline Intake Pressure Ratio & & inactive \\
\hline
\end{tabular}

\begin{tabular}{|l|l|}
\hline Pressure Ratio & \\
\hline
\end{tabular}

\begin{tabular}{|l|l|l}
\hline Burner Exit Temperature & K & 1530
\end{tabular}

\begin{tabular}{|l|l|l|}
\hline Burner Design Efficiency & & 0.999 \\
\hline
\end{tabular}

\begin{tabular}{|l|l|}
\hline Burner Partload Constant & 1 \\
\hline
\end{tabular}

\begin{tabular}{|l|l|l|}
\hline Fuel Heating Value & M. $/ \mathrm{kg}$ & 49.7365
\end{tabular}

\begin{tabular}{|l|l|l}
\hline Overboard Bleed & $\mathrm{kg} / \mathrm{s}$ & 0 \\
\hline
\end{tabular}

\begin{tabular}{|l|l|l}
\hline Power Offtake & kW & 30
\end{tabular}

\begin{tabular}{|l|l|}
\hline HP Spool Mechanical Efficiency & 0.998
\end{tabular}

\begin{tabular}{|l|l|}
\hline Burner Pressure Ratio & \\
\hline
\end{tabular}

\begin{tabular}{|l|l|l|}
\hline Turb. Interd. Ref. Press. Ratio & & 0.975 \\
\hline
\end{tabular}

\begin{tabular}{|l|l|l|l|l|}
\hline Turbine Exit Duct Press Ratio & 0.98 \\
\hline
\end{tabular}

\begin{tabular}{|l|l|l|l|}
\hline Nozzle Pressure Ratio & & 1.03 \\
\hline
\end{tabular}

Nozzle Thrust Coefficient

LP Spool Mechanical Efficiency

Nominal PT Spool Speed [RPM]

Close 5

C: $\backslash$ Users \Snow3 \DesktoplUniben Journal Manuscript \Model LM2500.CYS

\section{Figure 7}

Modeled design point. 


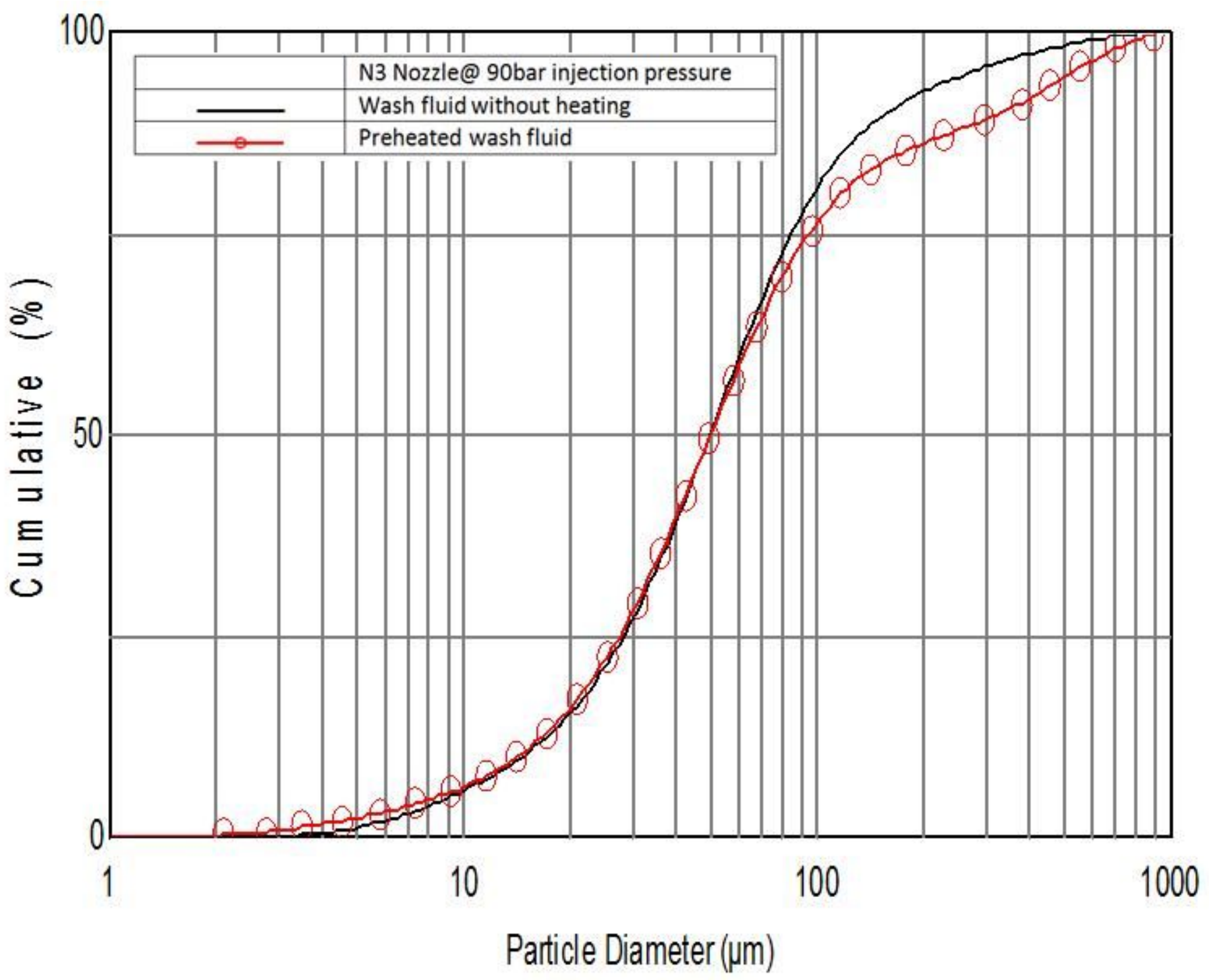

Figure 8

Cumulative distribution curves preheating the wash fluid and that without preheating at a given injection pressure. 


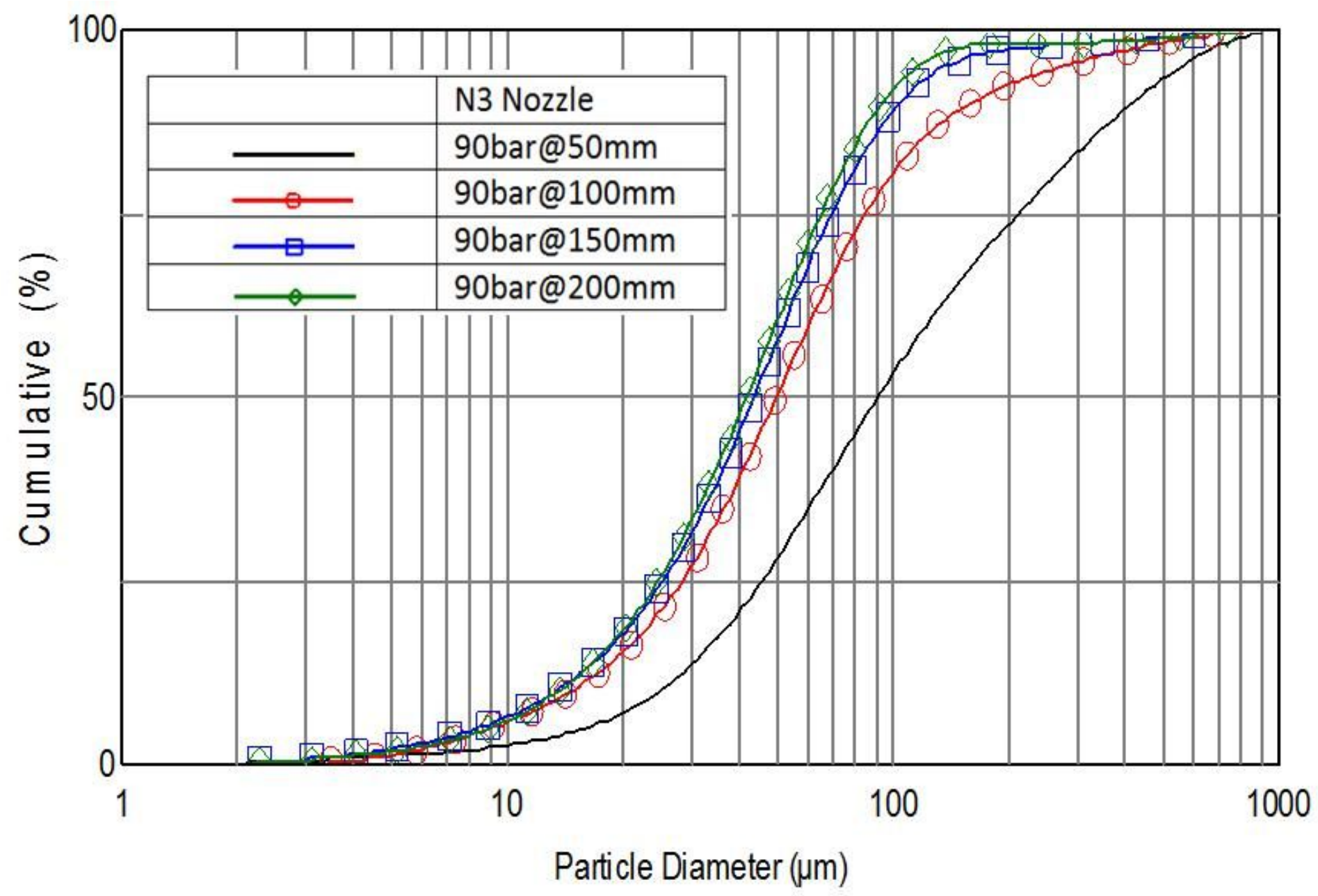

Figure 9

Cumulative distribution curves for varying injection distance. 


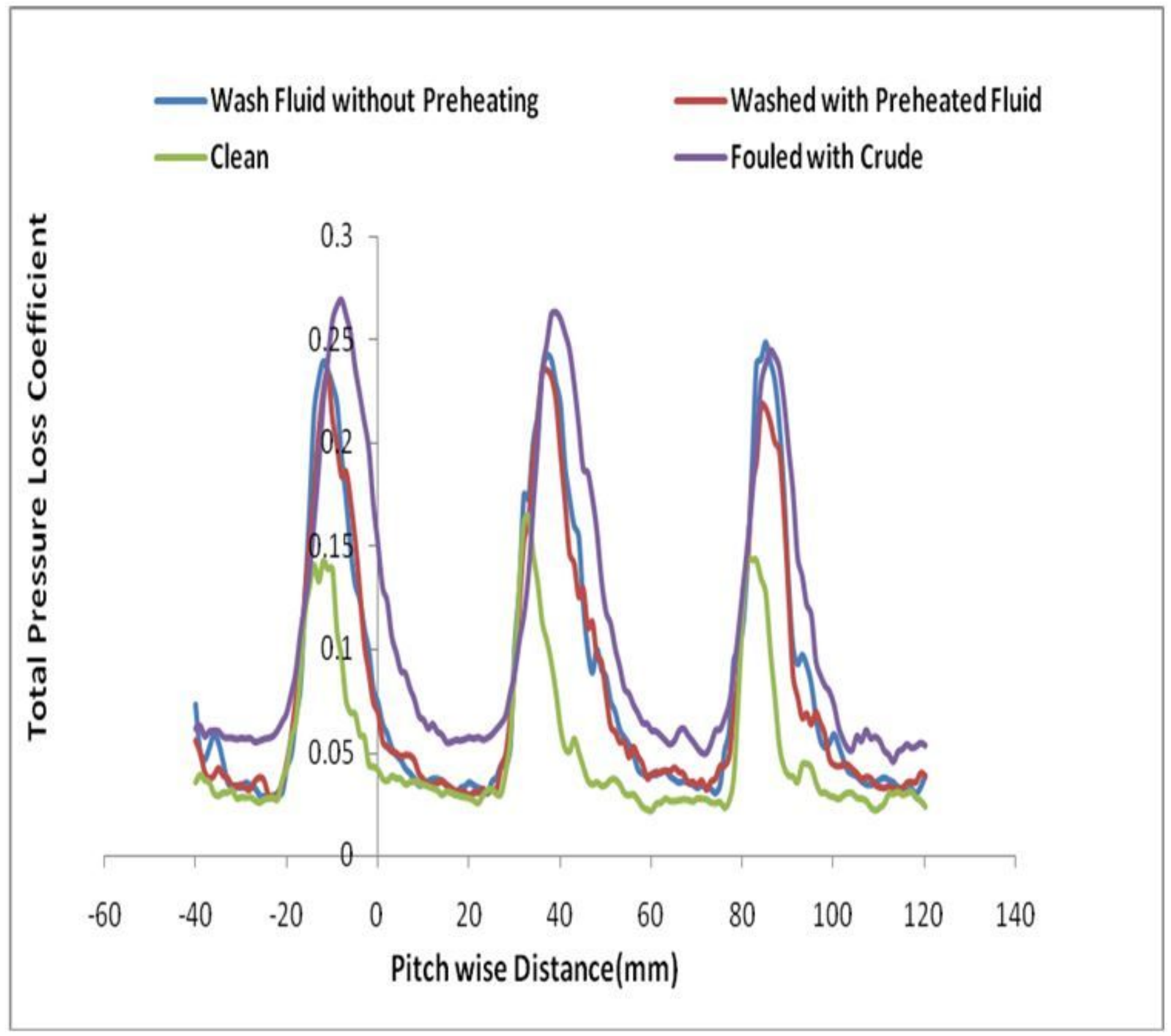

Figure 10

Total pressure loss coefficient against Pitch distance. 


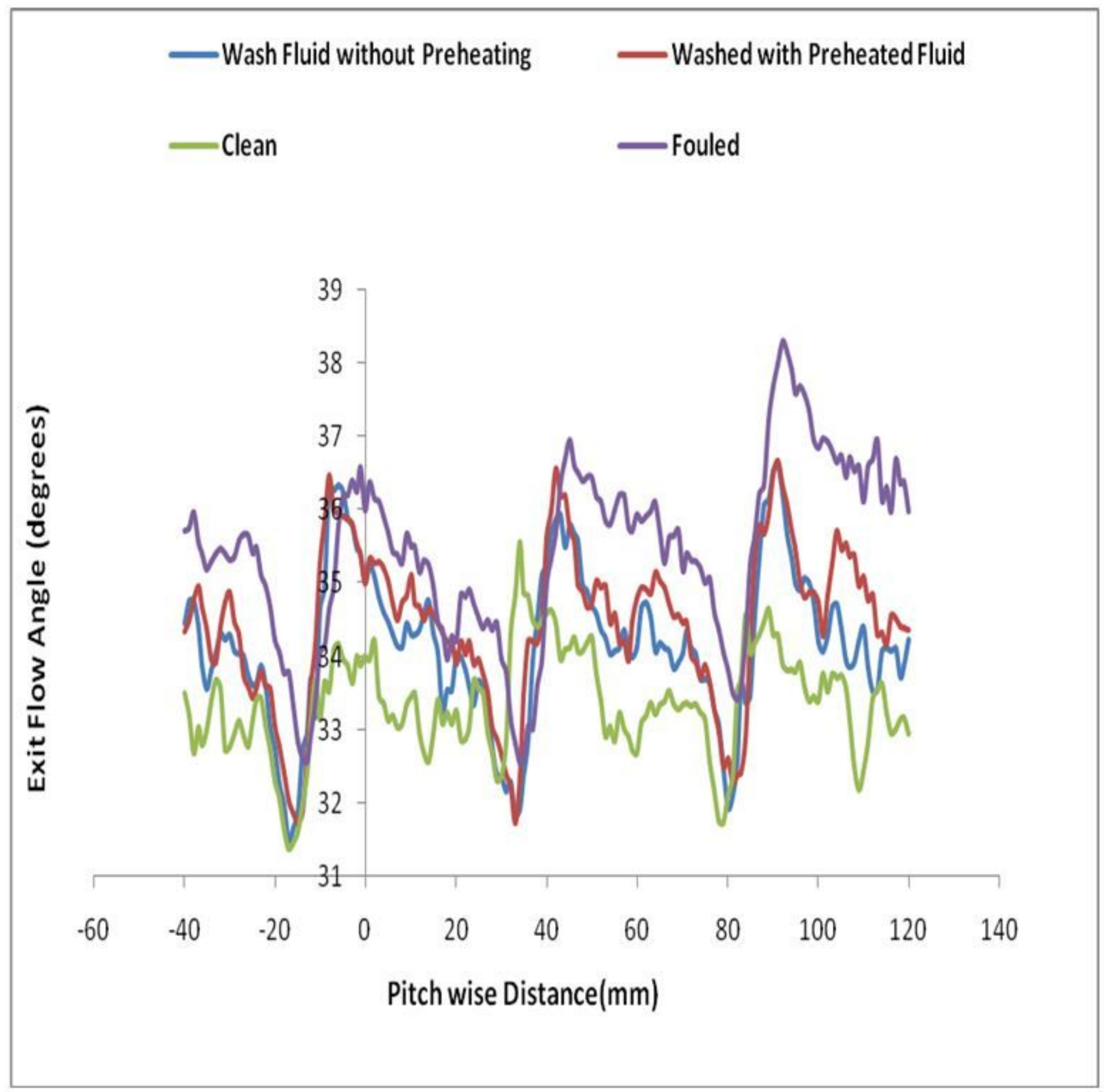

Figure 11

Exit flow angle against Pitch distance e. 


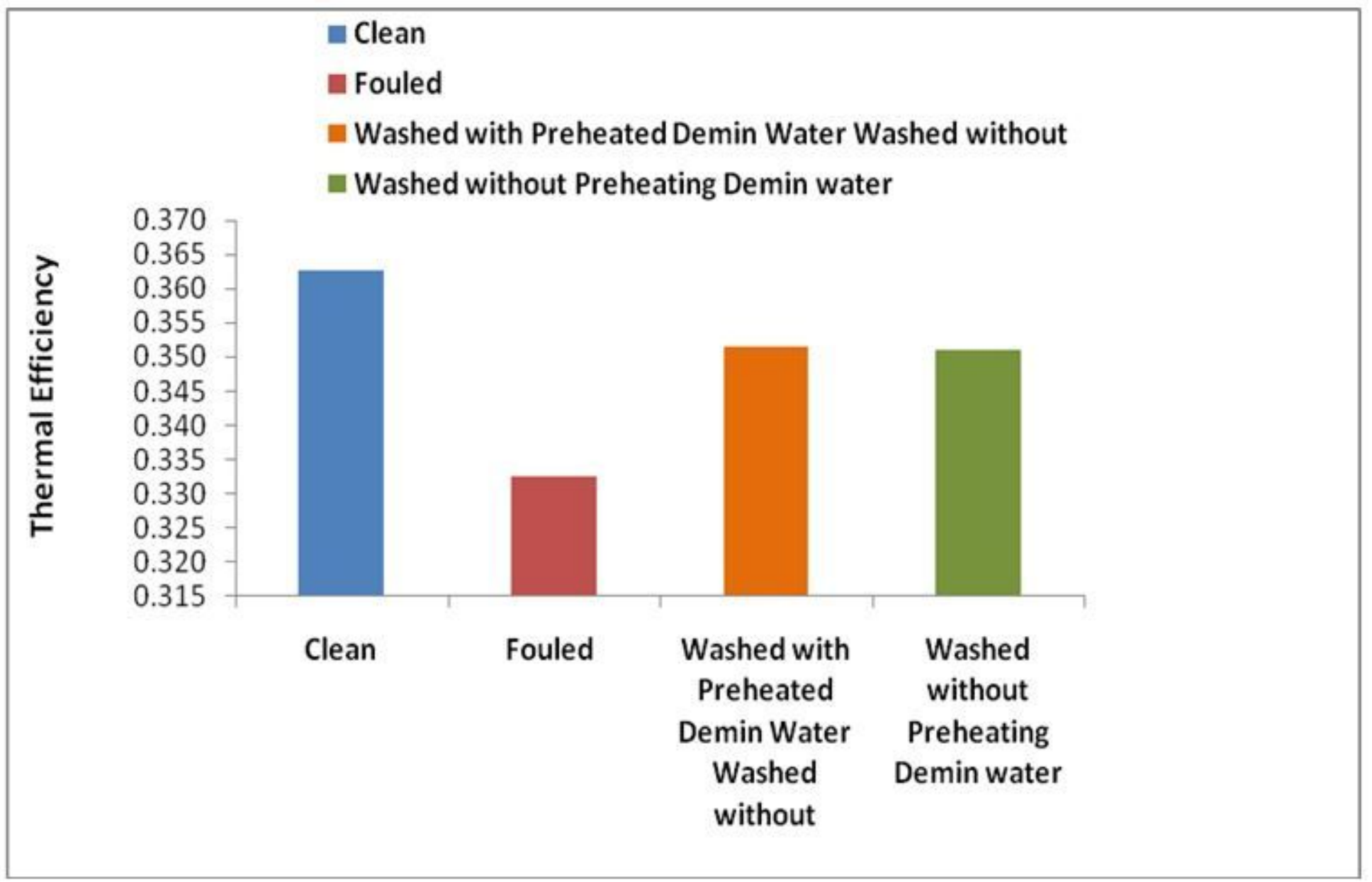

Figure 12

Plot of Thermal Efficient at Different Conditions. 


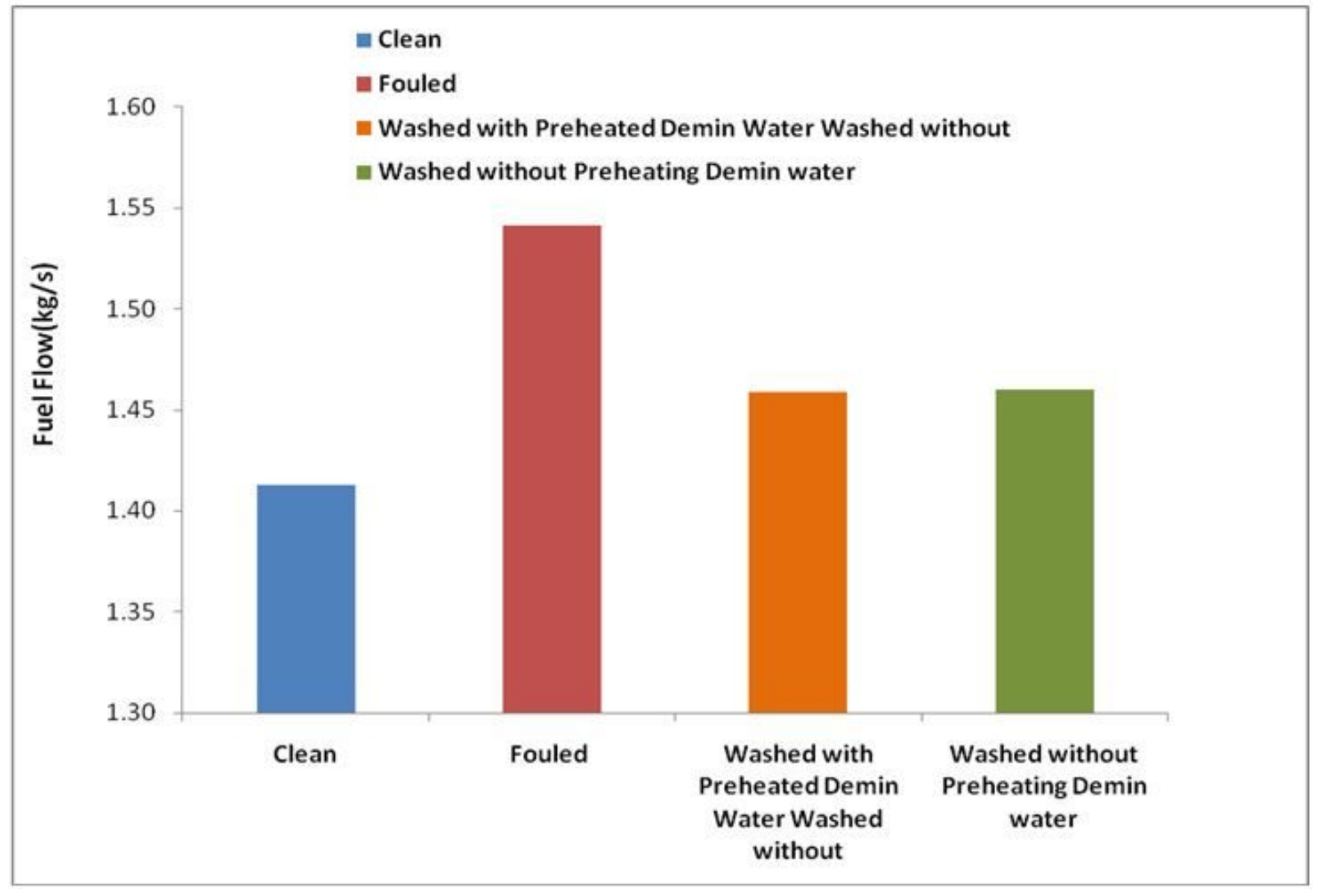

Figure 13

Plot of Fuel Flow at Different Conditions.

\section{Supplementary Files}

This is a list of supplementary files associated with this preprint. Click to download.

- CummulativeDistributionPlots.docx

- EnginePerformanceSimulationData.xIsx

- Aerodynamicsperformancedata.xlsx 